\title{
Correction to: Identification and characterization of complete genome sequence of Alfalfa mosaic virus infecting Gynostemma pentaphyllum
}

\section{Shuang Song • Huan Liu • Junhua Zhang • \\ Chunqing Pan $\cdot$ Zhengnan Li}

Published online: 24 February 2020

(C) Koninklijke Nederlandse Planteziektenkundige Vereniging 2020

Correction to: Eur J Plant Pathol (2019) 154:491-497

https://doi.org/10.1007/s10658-018-01647-1

Funding information should be correctly read as:

"Young Talents" Project of Northeast Agricultural University (No. 17QC05), and are NOT the former two ones 17QC05 and UNPYSCT-2018157.

The online version of the original article can be found at https://doi.org/10.1007/s10658-018-01647-1

S. Song $\cdot$ J. Zhang $\cdot$ C. Pan

Department of Plant Protection, College of Agriculture, Northeast Agricultural University, Harbin 150030, China

\section{Z. Li $(\bowtie)$}

College of Horticulture and Plant Protection, Inner Mongolia Agricultural University, Huhhot 010018, China

e-mail: lizhengnan@imau.edu.cn

H. Liu

State Key Laboratory of Crop Stress Biology for Arid Areas, College of Plant Protection, Northwest A\&F University,

Yangling 712100, China 